[Aus der hygienisch-chemischen Untersuchungsstation des X. Armeecorps zu Hannover.]

\title{
Ueber die Nothwendigkeit und die beste Art der Sputumdesinfection bei Iungentuberculose.
}

\author{
Von
}

\author{
Dr. Martin Kirchner,
}

Stabsarzt.

Die Nothwendigkeit der unschädlichen Vernichtung tuberculöser Sputa wird jetzt wohl von keiner Seite mehr bestritten; sie miss als um so dringender erscheinen, als nach neueren Untersuchungen die Haltbarkeit der Tuberkelbacillen noch grösser zu sein scheint, als man bislang annahm. Fand sie doch A. K. Ston $e^{\mathfrak{l}}$ in getrockneten Sputis noch nach 3 Jahren in lebensfähigem und virulentem Zustande.

Auch bei anderweitigen Sputis, so bei Pneumonie, Influeuza u. s. w. dürfte die sichere Desinfection derselben im Interesse der Seuchenprophylaxe dringend gebnten sein, wie auch $\mathrm{R}$. Pfeiffer. ${ }^{2}$ bei Besprechung des Influenzabacillus mit Recht betont.

Statt der Spuckgläser empfiehlt Stone für wohlhabendere Leute Speigefässe vo a Papier, die heutzutage sehr widerstandsfähig hergestellt werden und täglich zusammen mit dem Sputum verbrannt werden sollen. Für öffentliche Krankenhäuser ist diese Methode entschieden zu kostspielig, ganz abgeseben davon, dass derartige Speigefâsse den für den Kliniker sehr fühlba:en Fehler der Undurchsichtigkeit haben. Der weitere Vorschlag Stcne's, in der Armenpraxis Speigefüsse aus Zeitungspapier zu improvisiren, ist meines Erachtens nicht discutabel, da er zu Unsauberkeit führt und Uebertragungen eher begünstigt als verhindert.

1 Why the Sputa of tuberculous patients should be destroyed. The americ. journ. of the med. sciences. March 1891. (S. Centralblatt für Bacteriologie. Bd.X. S. 106.)

${ }^{2}$ R. Pfeiffer, Vorläufige Mittheilungen über die Erreger der Influenza. Deutsche medicinische Wochenschrift. 1892. S. 28. 
W. Prausnitz ${ }^{1}$ empfiehlt die Holzwolle als Füllmaterial für Spucknäpfe, welche das Sputum aufsaugt und den Vorzug grosse: Billigkeit besitzt (50 Kilo kosten $8 \mathrm{M}$., eine Speiglasfüllung etwa 1/5 Pf.). Die Verbandstofffabrik Gebr. Stiefenhofer in München-Sendling liefert sie gleich fertig in der Form, wie sie zur Füllung der Spuckgläser nöthig ist, und feuersicher imprägnirt. Die Desinfection soll in der Weise erfolgen, dass ,,der ganze Ballen nach erfolgter Benutzung in den Herd geworfen und verbrannt wird." Diese Art der Beseitigung des Sputums ist gewiss sehr praktisch, - aber dass es dabei sicher zu vermeiden sein sollte, dass nicht auch Sputum an die Wand und auf den Boden des Glases gelangt, scheint doch recht zweifelhaft. Und wenn dies der Fall - und das ist doch gewiss die Regel -, wie soll das Glas dann desinficirt werden? Prausnitz selbst empfiehlt hierfür den von mir angegebenen dpparat.

Vom Standpunkte des Klinikers aus ist übrigens auch gegen die Holzwolle als Füllmaterial dasselbe einzuwenden wie gegen die Speigefässe aus Papier, sie beeinträchtigt die Betrachtung und Untersuchung des Sputums.

Nach diesen Ausfïhrungen kann ich auch heute nur die Desinfection der Speigläser in strömendem Wasserdampf als die einzig sichere und daher hygienisch zulässige bezeichnen. Dass der von mir empfohlene billige und einfach zu bedienende Apparat ${ }^{2}$ anscheinend nicht die Beachtung gefunden hat, welche er nach meinen fortgesetzt günstigen Erfahrungen verdient, liegt vielleicht an dem nicht unbeträchtlichen Bruch von Speigläsern, welchen dieses Verfahren verursacht, und durch welchen dasselbe auf die Dauer etwas kostspielig wird. Jedoch lāsst sich derselbe, wie ich durch Monate hindurch fortgesetzte Versuche gefunden habe, durch zweckmässige Auswahl der Speigläser und vorsichtige Ausführung der Desinfection auf ein sehr geringes Maass herunterdrücken.

In den Königl. Garnisonlazarethen zu Münster und Würzburg, wo Versuche mit dem von mir angegebenen Apparat angestellt worden sind, ist nach den mir gewordenen Mittheilungen der Glasverlust sehr erheblich gewesen. In Münster sprangen bei sechs Versuchen von 30 Gläsern $\mathbf{7}=\mathbf{2 3} \cdot 3$ Procent derselben, während bei vier weiteren Versuchen, bei denen die Gläser zu $3 / 4$ mit Wasser gefüllt und auf einer Asbestplatte in den Apparat eingesetzt wurden, allerdings von 20 Gläsern keines zersprang.

Die von mir angestellten Versuche zeigen, wie gesagt, erstens, dass man durch zweckmässige Auswahl der Form der Gläser den Glasverlust erheblich herunterdrücken kaun.

${ }^{1}$ Münchener medicinische Wochenschrift. 1:91. Nr. 48.

2entralblatt für Bacteriotogie und Parasitenksinde. 1891. Bd. IX. S. 5. 
Durch gütige Vermittelung des Königl. Sanitätsamtes des X. ArmeeCorps war ich in der Lage, die im Garnisonlazareth zu Münster und die im Charité-Krankenhause za Berlin gebräuchlichen mit den hiesigen Speigläsern vergleichen zu können.

Die hier gebräuchlichen haben eine Höhe von 12 , einen oberen Durchmesser von 11 und einen grössten Durchmesser von $11.5^{\mathrm{cm}}$, sind farblos, ohne Blasen, schön geschweift und haben einen Boden, der nur wenig dicker ist als die Seitenwandungen. Die Gläser aus Münster dagegen haben eine Höhe von 13 , einen oberen Durchmesser von 10, einen grössten Durchmesser von $11.5^{\mathrm{cm}}$, die Farbe ist grünlich, die Schweifung plump, der Boden stark verdickt. Diese Gläser sind also offenbar minderwerthig und erklären das ungünstige Bruchverhältniss (23.3 Procent) zur Genüge. Auch die Gläser aus der Charité stehen den hier gebräuchlichen nach; sie haben einen stark verdickten Rand, einen auffallend dicken Boden, der obere Durchmesser beträgt 12 , der untere 11 , die Höhe $15.5 \mathrm{~cm}$, die Farbe ist weissgrau.

Auf der mir unterstellten Tuberculosen-Abtheilung wurden in meinem Apparat in der Zeit vom 2. bis 24. März d. J. 241 Charitégiäser desinfcirt, von denen $13=5 \cdot 39$ Procent zersprangen. In der Zeit rom 27. October v. J. bis 1. März d. J. wurden 950 der hier gebräuchlichen Speigläser auf gleiche $W^{T}$ eise desinficirt; von ihnen zerspringen $45=$ 4. 74 Procent.

Dies zeigt zur Genüge, dass der Glasverlust beim Desinficiren durch die Wahl eines entsprechend geformten und aus einem möglichst guten Glasflusse hergestellten Speiglases wesentlich verringert werden kann. $\mathrm{Ob}$ es möglich ist, für den Preis von 15 Pfennigen - so viel kosten die im hiesigen Lazareth üblichen Speigläser beim Massenbezuge pro Stück ein noch besseres Glas herzustellen, entzieht sich meiner Beurtheilung.

Ich habe aber weiter zu zeigen versucht, dass der Glasverlust noch abhängt von der Ausführung der Desinfection. Zu diesem Zwecke wurden von den hiesigen Gläsern:

1. Zweimal je 10 mit etwas Sputum und 400 con Wasser von $14^{\circ} \mathrm{C}$. gefüllte Gläser in den Apparat vor Erhitzen desselben (bei $14^{\circ}$ C.) gesetzt, mit ihm zusammen erhitzt und von dem Augenblicke ab, wo der Dampf strömte, und das Thermometer $100^{\circ} \mathrm{C}$. zeigte, $1 / 2$ Stunde lang darin belassen. Von diesen 20 Gläsern sprangen $2=10$ Procent.

2. Zweimal wurden je 10 mit Sputum theilweise gefüllte Gläser in dem Augenblicke, als der Dampf strömte, in den Apparat gesetzt und $1 / 2$ Stunde in demselben belassen. Von diesen 20 Gläsern sprang $1=$ 5 Procent. 
3. Viermal wurden je 10 mit etwas Sputum und $400^{\mathrm{cem}}$ Wasser von $40^{\circ} \mathrm{C}$. gefüllte Gläser in dem Augenblicke, als der Dampf strömte, in den Apparat gesetzt und $1 / 2$ Stunde darin belassen. Von diesen 40 Gläsern sprangen $2=5$ Procent.

4. Viermal wurden je zehn mit etwas Sputum gefüllte Gläser in den Appararat vor Erhitzen desselben (bei $14^{\circ} \mathrm{C}$.) gesetzt, mit ihm zusammen erhitzt und von dem Augenblicke ab, wo der Dampf strömte, und das Thermometer $100^{\circ} \mathrm{C}$. zeigte, $1 / 2$ Stunde lang darin belassen. Von diesen 40 Gläsern sprangen $4=2 \cdot 5$ Procent.

Somit liess sich durch zweckmässige Art der Desinfection der Glasverlust, der auf der Station unter den Händen der Lazarethgehülfen 4.74 Procent betrug, im Laboratorium auf 2.5 Procent herabdrücken. Bei den Charitégläsern sah ich sogar bei entsprechenden Versuchen im Laboratorium von 40 desinficirten kein einziges springen. Dies liegt zum grossen Theile daran, dass die Gehülfen entweder die Gläser kalt in den heissen Apparat hineinstellen oder noch heiss aus demselben an die Luft bringen. Beides ist $\mathrm{zu}$ vermeiden.

Als zweckmässigste Methode ist also zu empfehlen, die Gläser kalt in den noch nicht erhitzten Apparat zu bringen und erst mit ihm zusammen zu erhitzen, sie $1 / 2$ Stunde rom Augenblick des Strömens des Dampfes $a b$ darin zu lassen, dann den Deckel zu lüften, die Gläser jedoch erst herauszunehmen, wenn sie bereits etwas abgekühlt sind. Dadurch wird allerdings die Zeit, welche das Desinfectionsverfahren beansprucht, etwas verlängert. Aber bei einiger Uebung der Leute fällt das nicht in's Gewicht.

Müssen mehr als zehn Gläser desinficirt werden, so dürfen, da der Apparat nur zehn gleichzeitig aufnehmen kann, beim zweiten Gange die Gläser nicht kalt in den heissen Apparat gebracht werden, sondern es empfiehlt sich, sie etwa zur Hälfte mit warmem Wasser (von ca. $40^{\circ} \mathrm{C}$.) zu füllen.

Dass die Tuberkelbacillen durch diese Art der Desinfection mit Sicherheit getödtet werden, habe ich durch mehrfache Impfversuche an Meerschweinchen zur Genüge festgestellt, auch war das nach den Versuchen von Schill und Fischer ja von vornherein anzunehmen.

Die Beschaffenheit des Apparates, welcher vom Klempnermeister Schulze in Hannover für 25 Mark geliefert wird, geht aus der Zeichnung zur Genüge hervor. Der nach dem Muster des Soxleth'schen Milchkochers aus starkem Weisshlech gebaute Kessel ist $42 \mathrm{~cm}$ hoch, hat einen Durchmesser von $40.3 \mathrm{~cm}$ und ein in jedes Heerdloch passendes Bodenstïck von $6^{\mathrm{cm}}$ Höhe und $29^{\mathrm{cm}}$ Durchmesser. Er besitzt zwei Einsätze 
von $18.4 \mathrm{~cm}$ Höhe und $39 \mathrm{~cm}$ Durchmesser, deren jeder aus zwei parallel über einander vermittelst sechs Säulen befestigten Blechscheiben besteht und auf drei $4.8 \mathrm{~cm}$ langen hohlen Füssen steht. Die untere Scheibe hat zahlreiche Löcher für den Durchtritt des Dampfes, die obere fünf kreisförmige Ausschnitte von $12.6^{\mathrm{cm}}$ Durchmesser für die Speigläser, so dass also im Apparat jedes Mal 10 Gläser gleichzeitig sterilisirt werden können.

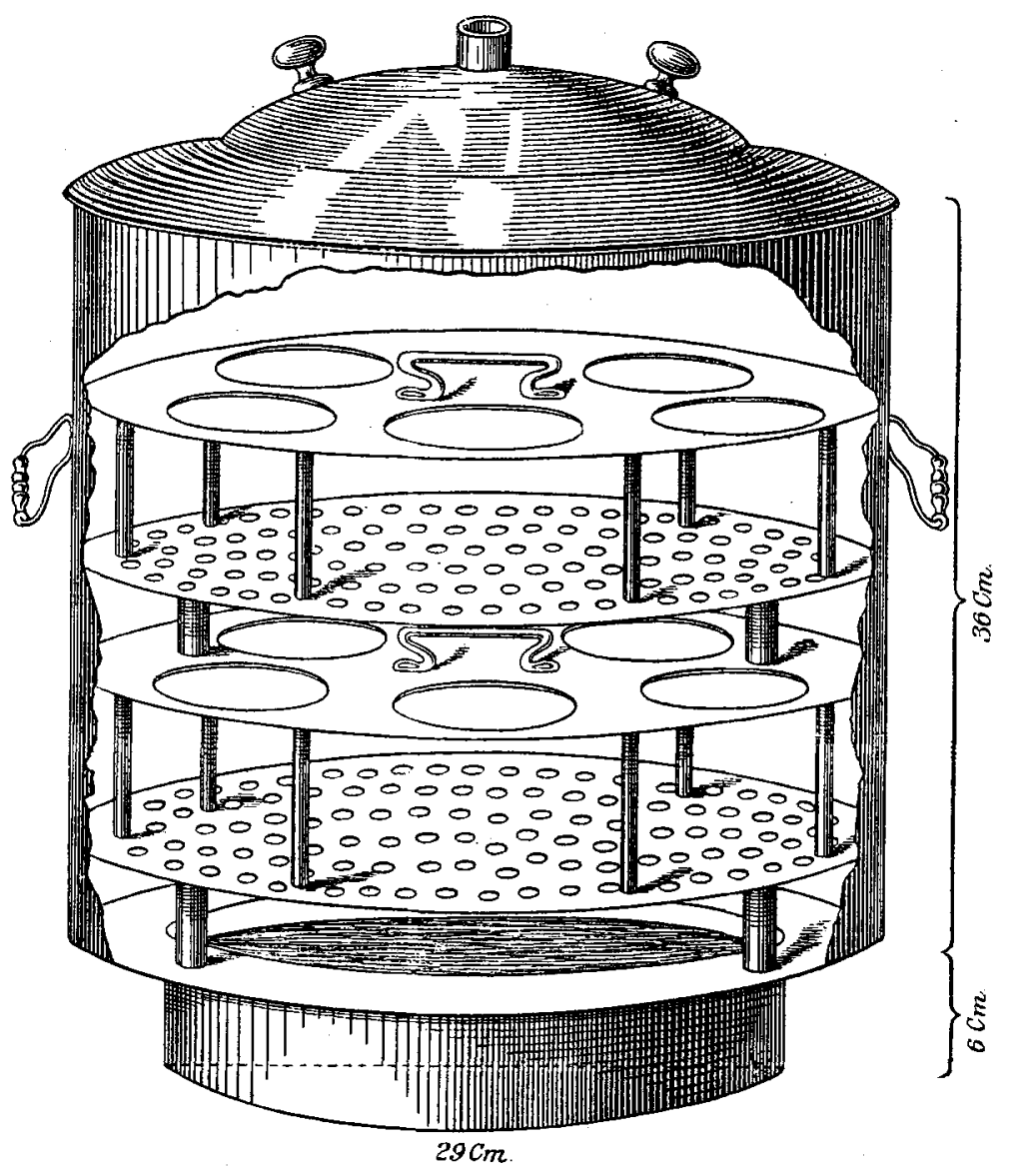

Der Boden wird am zweckmässigsten aus Kupfer hergestellt. Der Deckel hat zwei Knnöpfe zur Handhabe und einen Tubus für das Thermometer.

Der Apparat wird auf einem gewöhnlichen Kochherd erhitzt, und sind dazu täglich $8 \cdot 5$, also im Laufe eines Jahres etwa $3100^{\mathrm{kg}}$ Kohlen erforderlich, eine Ausgabe, die im Vergleich zu der Wichtigkeit ihres Zweckes nicht in Betracht kommen kann. 
Auch wenn wir den Glasverlust wirklich zu 5 Proc. der desinficirten Gläser annehmen - ich habe gezeigt, dass er bei geeignetem Verfahren erheblich geringer ist - , so würden, wenn durchschnittlich täglich zwölf Gläser desinficirt würden, in einem dem hiesigen Lazareth an Grösse gleichkommenden Krankenhause (240 Betten) jährlich etwa 220 Gläser springen; was einer Ausgabe von 33 Mark entspräche.

Wenn wir uns erinnern, wie viele Krankenwärter und Krankenpflegerinnen erfahrungsgemäss in ihrem Berufe Opfer der Tuberculose werden; wenn ich nachweisen konnte, dass die Lazarethgehülfen und Krankenwärter der Armee mehr als zwei- bis dreimal so häufig an Tuberculose erkranken als die übrigen Soldaten; wenn wir endlich . bedenken, dass durch die Tuberculinbehandlung die Prognose der Tuberculose wenigstens in den Anfangsstadien allerdings erheblich gebessert, im Ganzen aber noch immer eine recht traurige ist, dann müssen wir jedes Mittel, welches geeignet ist, die Verbreitung der Tuberculose zu verhüten, mit Freuden begrüssen. Es wäre in der That sehr zu beklagen, wenn die als einzig zweckmässiges Verfahren anerkannte Desinfection des Sputums vermittelst strömenden Wasserdampfes wegen der dadurch verursachten, immerhin doch nur geringen Kosten eine weitere Verbreitung nicht finden sollte.

Zum Schluss kann ich mir nicht versagen, einige Beobachtungen mitzutheilen, welche die Infectiosität des tuberculösen Sputums auf das grellste beleuchten. Ein junges Mädchen verletzte sich am Mittelfinger mit dem Scherben eines Speiglases; in dem ein höchst bacillenreiches phthisisches Sputum sich befand, und bekam eine tuberculöse Tendinitis mit Tuberculose der Cubital- und Axillardrüsen (Tseherning). ${ }^{1}$ - Eine Krankenwärterin, welche phthisische Patienten pflegte, bekam atonische Geschwüre an den Fingern und Anschwellung der Axillardrüsen, in denen Tuberkelbacillen nachgewiesen wurden (Holst). ${ }^{2}$ - Eine Wärterin bekam ein tuberculöses Geschwür des rechten Augenlides, nachdem sie an dem Tage, an welchem sie einen Phthisiker abgewaschen, sich eine Alnepustel am Auge abgekratzt hatte (v. Eiselsberg). ${ }^{3}$ - Eine 26 jährige Frau, die ihren an Phthisis gestorbenen Mann während der letzten sechs Monate seines Lebens gepflegt hatte, bekam zwei Monate nach seinem Tode tu-

\footnotetext{
1 Fortschritte der Medicin. 1885. S. 65.

2 The Lancet. 1886. 16. October.

3 Wiener medicinische Wochenschrift. 1887. Nr. 53.
} 
berculöse Geschwüre an den Fingern und eine Spitzeninfiltration (Merklen). ${ }^{1}$ - Weitere Infectionen von Wäscherinnen nach dem Reinigen der Wäsche von Phthisikern berichten Steinthal, ${ }^{2}$ v. Lesser ${ }^{3}$ u. A. Der Auswurf der Schwindsüchtigen ist die Hauptquelle der Ansteckung mit Tuberculose, seine unschädliche Beseitigung daher eine der wichtigsten Forderungen der Hygiene.

\footnotetext{
1 Revue des sciences méd. 1888. Nr. 52.

2 Deutsche medicinische Wochenschrift. 1888. Nr. 10.

3 Ebenda. 1888. Nr. 29.
} 